\title{
Which patients should have exercise testing after myocardial infarction treated by thrombolysis?
}

Exercise testing in the early recovery period after myocardial infarction has been widely investigated, reviewed, and recommended in the evaluation of the prognosis of infarct survivors. ${ }^{12}$ Several exercise test variables have been suggested as markers of high risk of subsequent cardiac events, including early onset angina during the exercise test, early onset of ST segment depression, or a compromised haemodynamic response to exercise. These data, however, were collected before the widespread use of thrombolysis in the treatment of myocardial infarction.

The value of risk stratification by exercise testing in the thrombolytic era has recently been questioned. On page 415 Stevenson and coworkers suggest that treadmill testing is of limited value for identifying high risk patients. ${ }^{3}$ They prospectively studied 256 consecutive patients with acute myocardial infarction treated by thrombolysis who had early reinfarction. Recurrent ischaemic events-that is, unstable angina, reinfarction, and death-occurred in $41(16 \%)$ of 256 patients and a further nine required revascularisation. ST depression at a low workload and low exercise tolerance were predictive of recurrent events but at a poor positive predictive accuracy. None of the other exercise test variables was associated with recurrent ischaemic events and the authors conclude that treadmill stress testing is of limited clinical value.

On the other hand Stevenson et al clearly acknowledge that the negative predictive accuracy is $89 \%$. Thus a negative response clearly identifies a group of patients at low risk. This is as important an aspect of an exercise test as a positive response. Such patients can be confidently reassured that all is well and then perhaps discharged to be treated by their general practitioners without further cardiological follow up. This facet of exercise testing after myocardial infarction in patients given thrombolysis is emphasised by Cross et al on page 428 . They studied a group of younger infarct patients of whom more than $70 \%$ received thrombolysis. ${ }^{4}$ They showed that patients who do not have cardiac pain or ST/T wave changes on exercise testing have an excellent prognosis and they maintain that further investigation is not required. But in this study exercise testing was performed a mean of 60 days after the initial myocardial infarction. This late testing may have biased the results.

Clearly, outcome was good in the patients in both study groups. The mortality at 10 months reported by Stevenson et al was just under $2 \%$, and $8 \%$ sustained a reinfarction during follow up. The mortality reported by Cross et al was similar, and half of the patients had essentially normal coronary arteries or single vessel disease. Even after thrombolysis the severity of coronary artery disease and left ventricular dysfunction influence outcome. Nonetheless, left ventricular function is preserved as a result of thrombolysis ${ }^{5}$ and studies of the younger age group treated with thrombolysis show that few of these patients have severe extensive multiple vessel disease. These data therefore are clearly weighted in favour of a good outcome. By definition the value of the exercise test as a predictor of a poor outcome will be limited because of the low pre-test likelihood of a poor outcome. In a wider post-myocardial infarction population with a higher pre-test likelihood of adverse outcome exercise testing will have quite a different predictive capability. Furthermore, intervention by either angioplasty or coro- nary bypass surgery will inevitably modify the natural history in survivors of myocardial infarction. In Stevenson et al's series few patients underwent revascularisation (nine of 256 patients, $4 \%$ ) but these might have been the patients at highest risk, whereas in the series of Cross et al $32(17 \%)$ of 186 patients underwent revascularisation.

Should we then forget about exercise testing after thrombolysis in low risk patients? If so, what should replace it? Should we offer coronary angiography to all survivors of acute myocardial infarction who have had thrombolytic therapy? Certainly the available information does not support such an approach. There is little evidence that angiography for survivors of acute myocardial infarction alters eventual outcome in the acute phase $^{6}$ and recent data support a more conservative approach in which coronary angiography and revascularisation are reserved for those with overt persisting ischaemia in the later phase. ${ }^{7}$

On balance it seems that exercise testing after myocardial infarction still has a place in the thrombolytic era. However, the pre-test likelihood of adverse outcome is crucial to its clinical role. In those likely to have a good outcome, such as younger patients with first infarcts, it may be useful to be able to identify a cohort of patients at extremely low risk who can be reassured that all is well and discharged from hospital follow up. On the other hand in such a population it seems unrealistic, because of the relatively poor positive predictive accuracy of the exercise test, to offer coronary angiography to every patient with a positive test. Even in those patients with "high" risk tests, outcome in terms of mortality seems excellent. Perhaps it would be wiser simply to offer a routine follow up to such patients with a positive test and to offer early invasive investigation with a view to intervention to those who have persisting symptomatic ischaemia?

Birmingham Heartlands Hospital,

R G MURRAY

Bordesley Green East,

Birmingham B9 $5 S S$

1 Guidelines for Exercise Testing. A report of the American College of Cardiology/American Heart Association Task Force on Assessment of Cardiology/American Heart Association Task Force on Assessment of Diagnostic and Therapeutic Cardiovascular Procedures
on Exercise Testing). $\mathcal{F} \mathrm{Am}$ Coll Cardiol 1986,8:725-38.

2 Guidelines for the early management of patients with acute myocardial infarction. A report of the American College of Cardiology/American Heart Association Task Force on Assessment of Diagnostic and Therapeutic Cardiovascular Procedures (subcommittee to develop guidelines for the early management of patients with acute myocardial infarction) 7 Am Coll Cardiol 1990;16:249-92.

3 Stevenson R, Umachandran V, Ranjadayalan K, Wilkinson P, Marchant $\mathrm{B}$, Timmis $\mathrm{AD}$. Reassessment of treadmill stress testing for risk stratification in parients with acute myocardial infarction treated by thrombolysis. Br Heart f 1993;70:415-20.

4 Cross SJ, Lee HS, Kenmure A, Walton S, Jennings K. First myocardial infarction in the under 60 year old: the role of exercise testing and symptoms in deciding whom to catheterise. $B r$ Heart $\mathcal{f} 1993 ; 70$ : 428-32.

5 White HD, Norris RM, Brown MA, et al. Effect of intravenous streptokinase on left ventricular function and early survival after myocardial nase on left ventricular function and

6 Topol EJ, Califf RM, George BS, et al. A randomised trial of immediate opol EJ, Califf RM, George BS, et al. A randomised trial of immediate
versus delayed elective angioplasty after intravenous tissue plasminogen versus delayed elective angioplasty after intravenous tissue plasminogen

7 Rogers WJ, Babb JD, Bain DS, et al. Selective versus routine predischarge coronary arteriography after therapy with recombinant tissue-type plasminogen activator, heparin and aspirin for acute myocardial infarction. f Am Coll Cardiol 1991;17:1007-16. 